\title{
Endoscopic management of non-ampullary duodenal adenomas
}

\section{(ㄷ)(1) $\odot$}

\author{
Authors \\ Institutions \\ 1 Gastroenterology Department, Cochin Hospital, \\ Assistance Publique - Hôpitaux de Paris, France \\ 2 Gastroenterology Department, Beaujon Hospital, \\ Assistance Publique - Hôpitaux de Paris, France \\ 3 University of Paris, France. \\ 4 Radiology Department, Cochin Hospital, Assistance \\ Publique - Hôpitaux de Paris, France \\ 5 Pathology Department, Cochin Hospital, Assistance \\ Publique - Hôpitaux de Paris, France \\ submitted 4.5.2021 \\ accepted after revision 19.10.2021

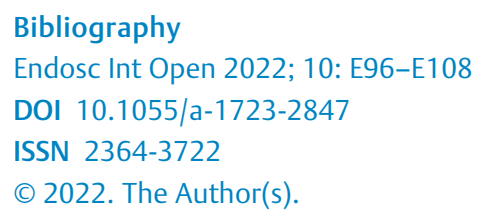

Maxime Amoyel ${ }^{1}$, Arthur Belle ${ }^{1}$, Marion Dhooge ${ }^{1}$, Einas Abou Ali ${ }^{1,3}$, Rachel Hallit ${ }^{1,3}$, Frederic Prat ${ }^{2,3}$, Anthony Dohan $^{3,4}$, Benoit Terris ${ }^{3,5}$, Stanislas Chaussade ${ }^{1,3}$, Romain Coriat ${ }^{*}, 1,2$, Maximilien Barret ${ }^{*, 1,2}$

\section{Introduction}

Duodenal polyps are the most frequent lesions in the duodenum, most of them incidentally discovered during upper gastrointestinal endoscopy. Adenomas, Brunner's gland hyperplasia, gastric metaplasia, inflammatory polyps, lipomas, leiomyomas, gastrointestinal stromal tumors, hamartomas, lymphomas, carcinoids and other neuroendocrine tumors, are the main histological diagnoses that can be encountered. Endoscopic mucosal biopsies, endoscopic ultrasound (EUS), EUS-

\footnotetext{
* These authors contributed equally.
}

Corresponding author

Maxime Amoyel, Gastroenterology Department, Cochin

Hospital, 27 Rue du Faubourg Saint Jacques, Paris, France 75679

Fax: +33158412836

maximeamoyel@gmail.com

\section{ABSTRACT}

Duodenal polyps are found in $0.1 \%$ to $0.8 \%$ of all upper endoscopies. Duodenal adenomas account for $10 \%$ to $20 \%$ of these lesions. They can be sporadic or occur in the setting of a hereditary predisposition syndrome, mainly familial adenomatous polyposis. Endoscopy is the cornerstone of management of duodenal adenomas, allowing for diagnosis and treatment, primarily by endoscopic mucosal resection. The endoscopic treatment of duodenal adenomas has a high morbidity, reaching $15 \%$ in a prospective study, consisting of bleeding and perforations, and should therefore be performed in expert centers. The local recurrence rate ranges from $9 \%$ to $37 \%$, and is maximal for piecemeal resections of lesions $>20 \mathrm{~mm}$. Surgical resection of the duodenum is flawed with major morbidity and considered a rescue procedure in cases of endoscopic treatment failures or severe endoscopic complications such as duodenal perforations. In this paper, we review the existing evidence on endoscopic diagnosis and treatment of non-ampullary duodenal adenomas. guided fine-needle biopsy, and endoscopic resection can be required to make the diagnosis, assess the neoplastic potential of lesions, and guide a patient's management. Noticeably, the two most common duodenal lesions, inflammatory polyps and gastric heterotopia [1], do not have any neoplastic potential.

Most of the time, endoscopists stumble upon these lesions that are mainly asymptomatic. Symptoms related to duodenal polyps include iron deficiency anemia, gastrointestinal bleeding, abdominal pain or dyspeptic symptoms caused by duodenal obstruction. Duodenal adenomas are also diagnosed on screening endoscopies in patients with hereditary predisposi- 
- Table 1 Revised Vienna classification of gastrointestinal epithelial neoplasia [2].

\begin{tabular}{|l|l|l|}
\hline Category & Diagnosis & Clinical management \\
\hline 1 & Negative for neoplasia & Optional follow-up \\
\hline 2 & Indefinite for neoplasia & Follow-up \\
\hline 3 & $\begin{array}{l}\text { Mucosal low-grade neoplasia } \\
\text { Low-grade dysplasia } \\
\text { Low-grade adenoma }\end{array}$ & Endoscopic resection \\
\hline 4 & $\begin{array}{l}\text { Mucosal high-grade neoplasia } \\
\text { High-grade adenoma/dysplasia } \\
\text { Noninvasive carcinoma } \\
\text { Intramucosal carcinoma }\end{array}$ & Endoscopic resection or local surgical excision \\
\hline 5 & Submucosal invasion by carcinoma & Surgical resection \\
\hline
\end{tabular}

tion syndromes to gastrointestinal neoplasia, mainly familial adenomatous polyposis (FAP).

In 2002, the Vienna classification defined four histopathological categories for gastrointestinal epithelial lesions: negative for neoplasia; indefinite for neoplasia; mucosal low-grade neoplasia; mucosal high-grade neoplasia including noninvasive; and intramucosal carcinoma. These four groups define the further management of duodenal lesions, including endoscopic resection for low- and high-grade duodenal adenomas, as shown on $>$ Table 1 [2].

Duodenal adenomas involving the major papilla have potential to invade the common bile duct and main pancreatic duct, resulting in specific features at diagnosis step (clinical presentation with obstructive jaundice or acute pancreatitis, intestinal or biliopancreatic histology) and for therapy (risk of acute pancreatitis, biliary stricture, higher risk of perforation after endoscopic resection, potential indications of surgical ampullectomy even for dysplastic lesions in case of extension to the biliary or pancreatic ducts). Therefore, ampullary adenomas will not be discussed in this review.

\section{Pathophysiology}

The natural history of sporadic duodenal adenomas follows the adenoma-carcinoma sequence and seems to have the same pattern as colonic adenomas, however with a longer time to progression: in a retrospective study involving 46 patients, Okada et al. found that only $16 \%$ of untreated duodenal adenomas with low-grade dysplasia eventually developed high-grade dysplasia and $4.9 \%$ adenocarcinoma over a 28 months period [3].

Recently, several studies have suggested two major subtypes of duodenal adenomas, also termed superficial non-ampullary duodenal epithelial tumor or SNADET: intestinal (Itype) and gastric (G-type) types, based on expression of biomolecular markers [4-9]. I-type SNADET are the most frequent, can be found along the entire length of the duodenum, follow the typical adenoma-carcinoma sequence, and have a slower neoplastic progression. The pathophysiology of I-type SNADET involves a deregulation of Wnt/ $\beta$-catenin signaling, leading to onset and progression of adenomas [4]. Mutations in APC (adenomatous polyposis coli), a tumor suppressor gene, KRAS or
TP53, are the main causes of $\mathrm{Wnt} / \beta$-catenin pathway deregulation. The activation of the $\mathrm{Wnt} / \beta$-catenin pathway increases nuclear accumulation of $\beta$-catenin, leading to transcriptional activation of genes (T-cells factors) involved in cell apoptosis and proliferation [5,6]. G-type SNADET are characterized by their proximal location, a villous structure with a low glandular density, and can coexist with duodenal gastric heterotopia, gastric foveolar metaplasia, and/or Brunner's gland hyperplasia, sharing common gene mutations such as GNAS, with greater malignant potential [7-9].

\section{Epidemiology}

Sporadic adenoma general findings

Duodenal polyps are found in $1 \%$ to $4.6 \%$ of upper gastrointestinal endoscopies. The prevalence of duodenal adenomas ranges from $0.10 \%$ to $0.82 \%$ in retrospective studies $[1,10$, $11]$, and $0.34 \%$ in a prospective study [12]. In the vast majority of cases, sporadic duodenal adenomas are located in the posterior and lateral part of the second duodenum, at the level or distal to the major papilla. This distribution appears to be influenced by bile flow [13]. As a consequence, duodenal adenomas in the duodenal bulb or distal to the second duodenum are rarely encountered.

A recent analysis from the Japanese National Cancer Registry reported an incidence of non-ampullary duodenal neoplasms of 23.7 per 1 million person-years, of which half were superficial lesions amenable to endoscopic resection [14]. Importantly, this rate is much higher than the 2.9 to 4.3 per 1 million person-years incidence rate reported in earlier studies [14]. It could be attributable to advances in endoscopic equipment and increasing awareness of endoscopists for duodenal neoplasms.

\section{Sporadic adenoma and colorectal cancer}

Sporadic duodenal adenomas are associated with a higher incidence of colorectal adenomas and adenocarcinomas. In a retrospective study of 22 patients with duodenal adenomas, $72 \%$ had colorectal adenoma and $4.5 \%$ had colorectal adenocarcinoma [15]. These data are supported by a retrospective casecontrol study of 34 patients showing that colorectal neoplasia 
> Table 2 Spigelman score [23].

\begin{tabular}{|l|l|l|l|l|}
\hline Findings at duodenoscopy & $\mathbf{1}$ point & $\mathbf{2}$ points & $\mathbf{3}$ points \\
\hline Number of adenomas & $1-4$ & $5-20$ & $>20$ \\
\hline Size $(\mathbf{m m})$ & $1-4$ & $5-10$ & $>10$ \\
\hline Histology & Tubular & Tubulovillous & Villous \\
\hline Dysplasia & Low-grade & NA & High-grade \\
\hline Spigelman Score & 0 & $1-4$ & $5-6$ & II \\
\hline Spiegelman Stage & 0 & 1 & & III \\
\hline NA, not applicable & & & IV \\
\hline
\end{tabular}

(colorectal cancer, advanced adenoma and non-advanced adenoma) was significantly more frequent in the duodenal adenoma group ( $56 \%$ vs. $33 \%$; $P=0.03$ ) with an odds ratio of 2.4 (95\% $\mathrm{Cl}, 1.1-5.4)$ [16]. A meta-analysis published in 2014 including 37152 patients showed a positive association between sporadic duodenal adenomas and colorectal neoplasms ( $O R=2.59 ; 95 \%$ Cl, 1.64-4.11) [17]. In 2015, the American Society of Gastrointestinal Endoscopy recommendations suggest that a colonoscopy should be performed when a duodenal adenoma is diagnosed [18].

\section{Sporadic adenoma and small bowel polyps}

In a German prospective controlled study, 14 patients with a proven sporadic duodenal adenoma and 14 patients without duodenal adenoma had a small bowel capsule endoscopy: small bowel polyps were identified in eight vs. 0 patients in the control group. Despite its methodology, the small number of patients and the absence of histological confirmation of the small bowel polyps described at capsule endoscopy do not allow to make strong conclusions from this work [19]. Currently, there is no indication to perform a small bowel capsule endoscopy in case of sporadic duodenal adenoma.

\section{Non-sporadic adenoma}

\section{FAP syndrome}

FAP is an autosomal-dominant syndrome due to a germline deleterious variation of the APC tumor suppressor gene. This syndrome leads to development of several colorectal adenomas and is associated with a $100 \%$ risk of colorectal cancer in its classical form without prophylactic colectomy.

Non-ampullary duodenal adenomas are common in FAP. In a 20-year retrospective study, FAP-related adenomas represented $60 \%$ of the duodenal adenomas, with a younger age at diagnosis (39.5 vs. 66.5 years for FAP-related vs. sporadic, respectively), a longer follow-up duration (100 vs. 43 months), and a higher local recurrence rate (72.5\% vs. $52 \%$ ) [20].

Bülow et al. showed, in a prospective multicenter study of 368 patients with a median follow-up of 7.8 years, a $65 \%$ prevalence of duodenal adenoma at the first endoscopy in FAP patients and a cumulative incidence of $90 \%$ at 70 years. Cumulative incidence of duodenal adenocarcinoma was $4.5 \%$ at 57 years [21]. The follow-up data from 304 patients over 14 years showed a cumulative risk of duodenal adenomas of $88 \%$ (95\% $\mathrm{Cl}, 84-93)$ over life, and a cumulative duodenal cancer incidence at 75 years of $18 \%$ with a median age at cancer diagnosis of 56 [22].

The severity of duodenal adenomatosis in patients with FAP is estimated by the Spigelman Classification [23] described in 1989 and presented in the $>$ Table 2 . The main risk factors for development of duodenal cancer are the following: stage IV of the Spigelman classification; presence of high-grade dysplasia or a lesion size $\geq 10 \mathrm{~mm}$ (also taken into account in the Spigelman stage IV); ampullary adenoma with a villous component or high-grade dysplasia [22,24-27]. In a prospective study over $47.9 \pm 15.6$ months, Saurin et al. found a $50 \%$ risk of developing Spigelman stage IV duodenal adenomatosis, justifying to treat endoscopically duodenal adenomas in FAP patients over performing endoscopic surveillance alone [28]. Other works from the same group have demonstrated the possibility of downgrading the Spigelman score with repeated endoscopic treatment $[29,30]$.

Currently, management of duodenal adenomas in FAP patients relies on an endoscopic surveillance every 1 to 5 years according to Spigelman score and the presence of an ampullary lesion. Endoscopic management consists of resection of the most significant lesions to progressively downgrade the Spigelman's score [31].

\section{Non-FAP hereditary predisposition syndrome to gastrointestinal cancers}

Lynch syndrome (LS,) previously known as hereditary non-polyposis colorectal cancer, is an autosomal dominant syndrome caused by germline deleterious variation in one of the DNA mismatch-repair genes (MLH1, MSH2, PMS2 or MSH6 or EPCAM). It is associated with an increased risk of gastrointestinal cancers. Many studies suggest a lifetime risk for small bowel cancer ranging from $0.6 \%$ to $12.0 \%$ [32-35].

In a retrospective study from 2018, Hammoudi et al. found seven duodenal neoplasms (adenoma or adenocarcinoma) among 113 patients with LS, with a $4.4 \%$ prevalence of duodenal adenomas in this population [36]. Two prospective studies including 36 and 200 patients with LS assessed prevalence of small bowel neoplasms with small bowel capsule endoscopy 

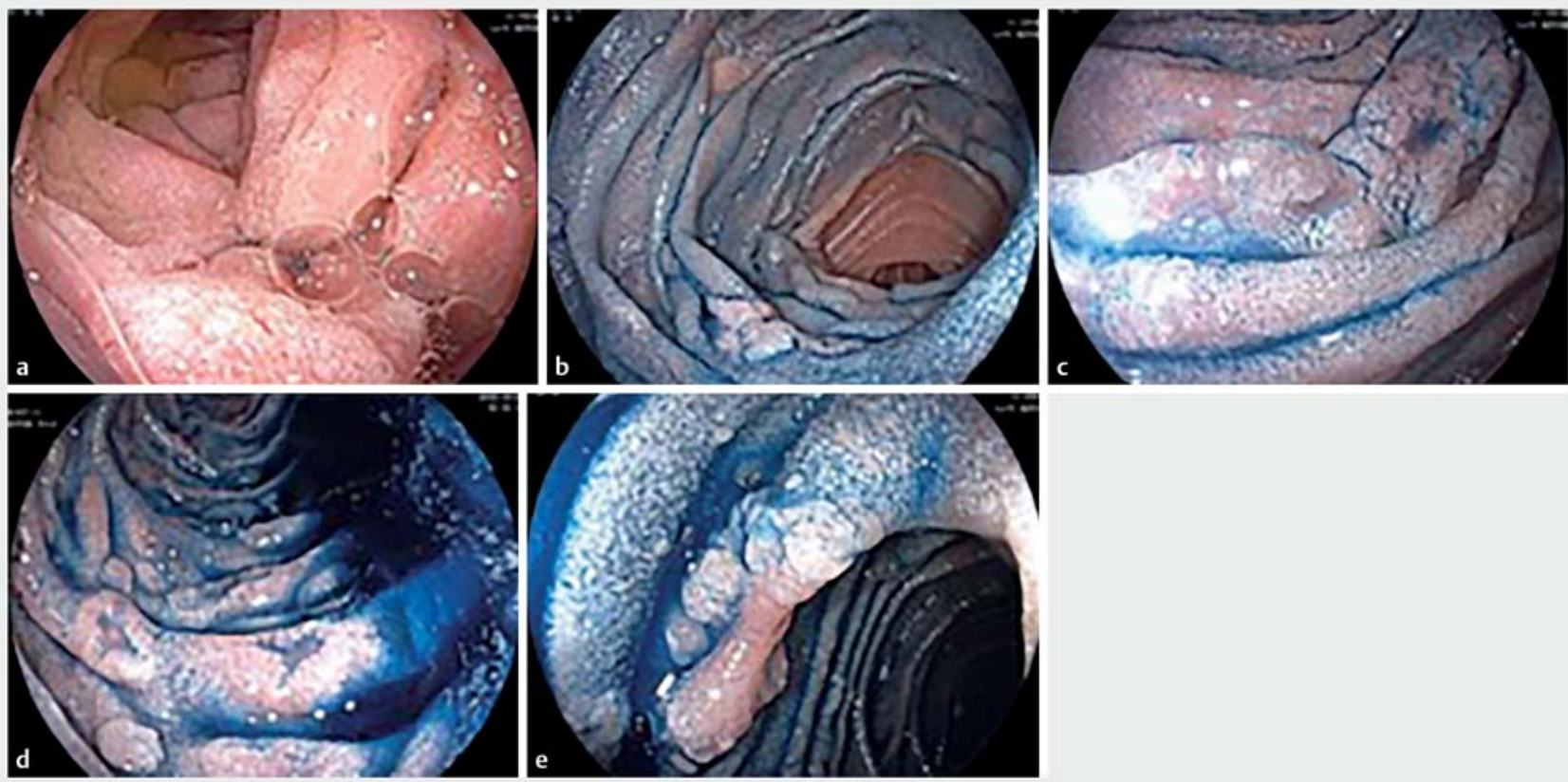

- Fig. 1 Duodenal evaluation of patient with FAP, in white light imaging alone (panel A) and after indigo carmine chromoendoscopy, showing multiple infracentimetric Paris 0-Ila duodenal adenomas (panel B-D) and one 10-mm Paris 0-Ila + Ilc adenoma at the genu inferius (panel E).

and found a duodenal neoplasm in $0.5 \%$ to $5.7 \%$ of patients $[36,37]$.

MUTYH Associated Polyposis (MAP) is an autosomal-recessive syndrome associating colonic adenomatous polyposis and an increased risk of duodenal adenomas with a prevalence estimated between $17 \%$ to $34 \%$ at a median age of 50 years. As in FAP, management of duodenal adenomas in MAP patients relies on an endoscopic surveillance every 1 to 5 years according to Spigelman score, also taking into account presence of a suspected ampullary lesion $[31,38,39]$.

Other rare inherited syndromes are associated with a higher risk of duodenal adenomas such as polymerases proofreading associated polyposis, associated with deleterious variations in the POLE and POLD1 polymerases genes $[40,41]$.

\section{Diagnosis}

\section{Endoscopic diagnosis: Detection}

Typically, non-ampullary duodenal adenoma is a unique sessile polyp, Paris 0 -Is (in $17.5 \%-57 \%$ of cases) or 0 -lla (in 30\%-65.3\% of cases), located in the second portion of the duodenum [4248]. Therefore, endoscopic assessment can require not only a conventional gastroscope, but also a side-viewing endoscope (duodenoscope) to thoroughly assess the left side of the descending duodenum and rule out an extension of the adenoma to the major papilla. A cap-fitted endoscope can be of help to best detect duodenal polyps between the duodenal folds. Of note, the distal attachment cap allows visualization of the major duodenal papilla with a standard gastroscope in a majority of patients [49]. One assessment of the distal duodenum, using a colonoscope, is advisable during the initial workup.
Chromoendoscopy using indigo carmine uniformly sprayed on the on duodenal mucosa with a dedicated catheter highlights all mucosal abnormalities. This technique is easy to use, cheap, and many studies [50-52] have shown its efficiency. Among these, a monocentric prospective study of 51 patients with FAP showed that indigo carmine chromoendoscopy improved the diagnostic yield of duodenal adenomas 3-fold, allowing an upstaging of the Spigelman stage ( $\bullet$ Fig. 1 ) [52].

\section{Characterization}

The main purpose of endoscopy is to characterize duodenal adenomas in the different categories of the Vienna classification and especially to distinguish C3 (low-grade dysplasia) and C4 ( high-grade dysplasia) from other categories [2].

Forceps biopsy have a low diagnostic performance for SNADETS: the diagnostic accuracy of endoscopic biopsy is only of $68 \%$ to $74 \%$ [45], and up to $20 \%$ of duodenal adenocarcinomas can be missed by biopsy alone $[53,54]$. In addition, endoscopic forceps biopsies may induce submucosal scarring and fibrosis, making subsequent endoscopic resection more difficult, and increase the risk of complications. Therefore, optical diagnosis of the lesion using virtual chromoendoscopy and magnification endoscopy is advisable. Several studies suggest endoscopic characteristics to differentiate low-grade from high-grade duodenal adenomas based on the pit pattern, vascular pattern, presence and distribution of the white opaque substance, and color and size of the lesions. A heterogenous, rough, nodular mucosal pattern or lack of a pattern, a network microvascular pattern, marginal distribution of a white opaque substance (resulting of an intramucosal accumulation of lipid droplets), diameter $>5 \mathrm{~mm}$, reddish color, and presence of a depressed 

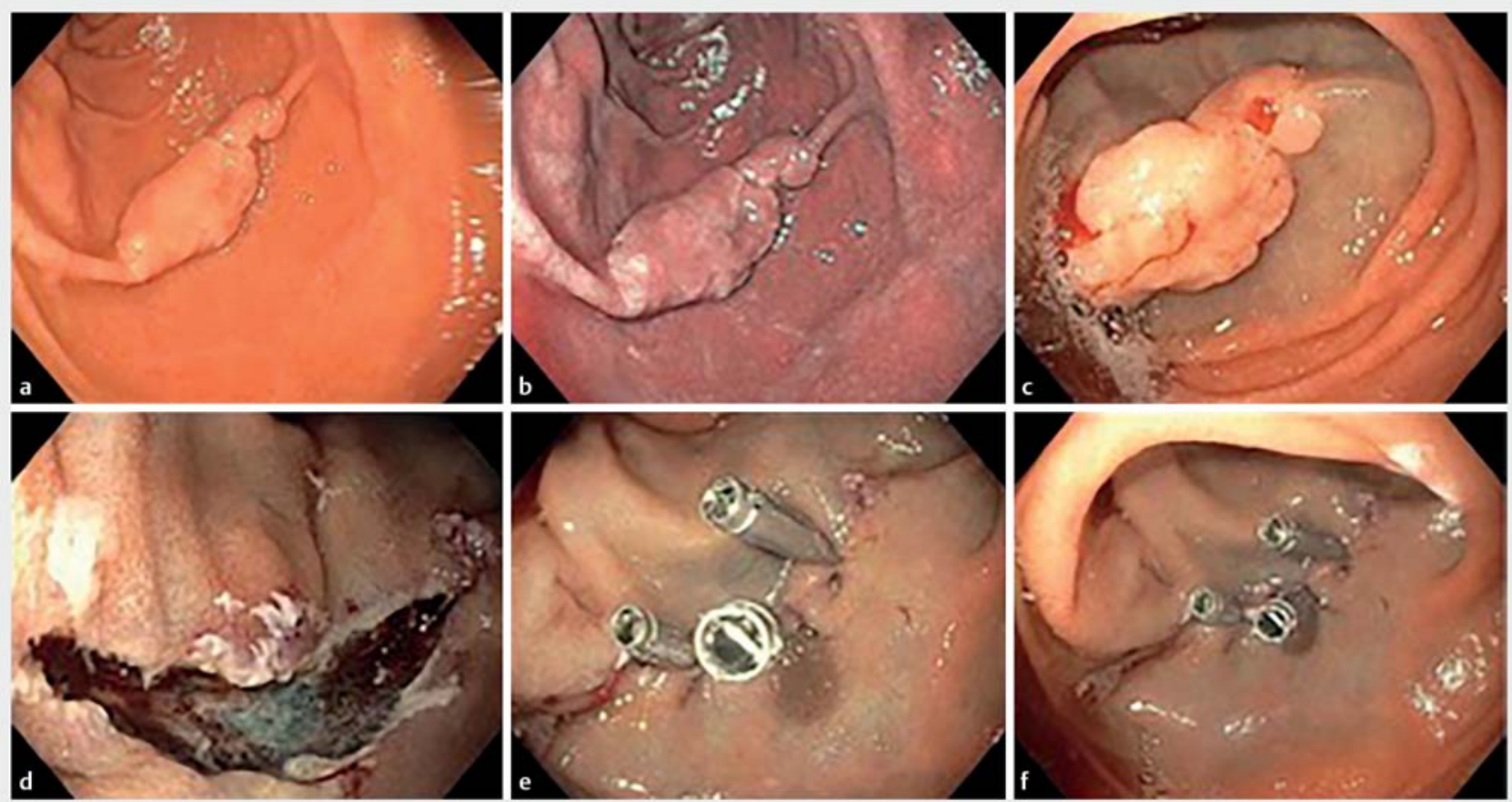

- Fig. 2 Endoscopic mucosal resection of a sporadic duodenal adenoma. a White-light endoscopic images showing a 15-mm Paris 0-is lesion in the second part of the duodenum. b virtual chromoendoscopy using narrow-band imaging. c Saline submucosal injection. $\mathbf{d}$ En bloc resection. e, $\mathbf{f}$ Clipping of the mucosal defect

area favor a duodenal adenoma harboring high-grade dysplasia) $[45,46,55-59]$.

Many algorithms and scores have been developed to distinguish C3 and C4 duodenal adenomas based on these characteristics with high diagnostic performance $[60,61]$.

\section{Other diagnostic modalities}

There is no specific guideline about use of endoscopic ultrasonography for non-ampullary duodenal adenomas. As in the rest of the upper digestive tract, endoscopic ultrasonography can be used to search for suspicious lymph nodes and assess the invasion depth of a duodenal lesion before endoscopic or surgical resection. In a retrospective study of 47 patients, Azih et al. showed that endoscopic ultrasonography predicted muscularis propria (T2 stage) invasion with a specificity of $88 \%$ and a negative predictive value of $90 \%$ [62]. Of note, duodenal adenocarcinoma is extremely rare, and the vast majority of duodenal neoplastic lesions are adenomas. In a large cohort of endoscopic resection for duodenal neoplasms, only $2 \%$ of the patients had invasive adenocarcinoma [43]. Finally, endoscopic ultrasonography is justified to rule out a muscularis propria invasion or the presence of suspicious lymph nodes in case of adenocarcinoma on biopsies, or endoscopic features suggestive of invasive adenocarcinoma, such as ulcerated or protruding lesion. In these cases, endoscopic resection should not be attempted and pancreaticoduodenectomy with lymph node resection is indicated.

Contrary to ampullary adenomas that can be suspected on CT-scanner in case of common bile duct and main pancreatic duct dilatation, duodenal adenomas are typically flat and rarely imaged by radiologists. They can appear as well-defined softtissue mass protruding or not in the duodenal lumen, sessile, surrounded by clear fat planes. After intravenous administration of contrast, they display homogeneous, mild enhancement [63].

\section{Treatment}

\section{Cold snare polypectomy}

Following the ESGE guidelines [64], cold snare polypectomy is recommended for small SNADET $<6 \mathrm{~mm}$. The evidence is initially based on the extrapolation from studies on colonic polyps, but increased recently with for small duodenal polyps, even in FAP syndrome [65-67].

A prospective study of 39 lesions ranging from 2 to $6 \mathrm{~mm}$ showed that cold snare polypectomy for small SNADET was effective and safe with an en bloc resection rate of $96.7 \%$, without any recurrence at 3 months and no complication (delayed bleeding or perforation) [68].

\section{Endoscopic mucosal resection technique}

Endoscopic mucosal resection (EMR) is the recommended treatment for duodenal adenomas $>6 \mathrm{~mm}$ ( $>$ Fig. 2). It is usually achieved with a forward-viewing endoscope (gastroscope or pediatric colonoscope) fitted with a distal attachment cap. However, the use of a side-viewing endoscope is optimal for resection of lesions on the medial part of the descending duodenum and provides excellent stability in the duodenum, while 
maintaining suction capacity due to the size of the endoscope and operating channel. Indigo carmine chromoendoscopy or virtual chromoendoscopy are frequently used to help delineating the lesion before resection. Perilesional marking with the tip of the snare is advisable, especially if the lifting solution contains epinephrine. Submucosal injection is performed using indigo carmine-stained saline or specific macromolecular solutions, as in the rest of the digestive tract, mixed or not with epinephrine to prevent procedural bleeding.

The choice of resection snare should take into account several parameters: the flat nature of most duodenal adenomas, requiring a rigid snare, high risk of bleeding following endoscopic resection; and the possibility of using the selected snare through a side-viewing endoscope. As a consequence, cold resection snares are widely used for smaller lesions $(<10 \mathrm{~mm})$, and 10 - to $15-\mathrm{mm}$ rigid snares such as monofilament snares are used for lesions $\geq 10 \mathrm{~mm}$. En bloc resection is sought whenever possible, usually for lesions $<20 \mathrm{~mm}$. In case of residual adenoma on the resection margins, cold snaring of the margins or ablation by argon plasma coagulation (APC) is performed. Endoscopic treatment success is defined by the absence of visible residual adenoma at the end of the endoscopic resection.

Cap-assisted EMR has been proposed as an alternative to conventional EMR, considering the flat morphology of the duodenal lesions $[69,70]$. Despite a reasonable $16.9 \%$ adverse event rate and a $1.7 \%$ reported perforation rate, this technique has not gained wide acceptance among gastrointestinal endoscopists, particularly owing to possible risk of perforation when suctioning the duodenal wall into the cap.

\section{EMR outcomes}

Several large retrospective studies $[43,44,48,71-75]$ and one recent prospective study [42] have reported outcomes of EMR for duodenal adenomas. The complication rate is highly dependent on median size of the lesions, while the recurrence rate, also influenced by lesions size and the possibility of en bloc endoscopic resection, is also potentially underestimated by retrospective series. The main findings of these works are summarized in > Table 3. In 2018, Tomizawa et al. reported a large series of endoscopic resections for sporadic non-ampullary duodenal adenomas, with 166 endoscopic resections and a median size of $20 \mathrm{~mm}$, they observed $11 \%$ major complications (only bleeding) and a $23 \%$ recurrence rate with a median follow-up of 1 year. The authors also determined that increasing size of the lesion, piecemeal resection, and inability to complete EMR were associated with adenoma recurrence $(P<$ 0.001). The prospective study from Augsburg including 118 adenomas with a median size of $15 \mathrm{~mm}$, of which 89 were nonampullary adenomas, recorded a $18 \%$ overall complication rates, including three perforations and one death. The recurrence rate was $20.4 \%$ at first follow-up endoscopy [42].

\section{Complications}

The two main complications following endoscopic resection of duodenal adenoma are bleeding and perforation. These complications are not specific to endoscopic resection in the duodenum. However, the duodenal wall is thin and the submucosal layer contains a high density or large blood vessels. Retrospective studies suggest that intraoperative and delayed bleeding occur respectively in $2.2 \%$ to $13.9 \%$ and $4.4 \%$ to $17.4 \%$ of cases and that the risk increases with the size of the polyp and the presence of a protruding lesion $[43,44,48,69,72-74,76]$. These rates are the highest of all endoscopic procedures. In this context, the European Society of Gastrointestinal Endoscopy (ESGE) guidelines [64] recommend discontinuing all antiplatelet therapy and vitamin $\mathrm{K}$ antagonists 5 days before the intervention (with a checked INR $<1.5$ for vitamin $\mathrm{K}$ antagonists) and direct oral anticoagulants 48 hours before intervention. The endoscopic resection is performed as an inpatient procedure with a two-night admission and daily complete blood count to check for bleeding signs. Anticoagulant or antiplatelet therapy is resumed within 48 hours after endoscopic resection.

Intraprocedural bleeding is managed immediately. Thermocoagulation with the tip of the resection snare or a coagulating forceps is highly effective, but may result in delayed perforations related to the thermal damage to the duodenal wall. Placement of hemoclips is the optimal way to achieve hemostasis, but can be technically challenging when using a side-viewing endoscope, might jeopardize the final steps of the resection, and is not always feasible in cases of extensive resections.

Delayed bleeding is a more challenging complication. It can occur in up to one-third of the patients, and is mainly correlated to the size of the resection. Management always involves emergent upper gastrointestinal endoscopy, often red blood cell transfusion and intensive care admission, and sometimes interventional radiology, while surgery has no role. Although the most bleeding occurs within 48 hours, major delayed bleeding has been reported up to 7 days after resection [42]. Therefore, patients should be aware of this complication and of the telephone number to call in case of melena, hematochezia, or unusual fatigue. Aschmoneit-Messer et al., in a retrospective study of 50 patients with duodenal EMRs, showed that prophylactic argon plasma coagulation therapy of the resection bed for adenomas $>20 \mathrm{~mm}$ and/or in case of visible vessels $\geq 1 \mathrm{~mm}$, lowered the risk of delayed bleeding [77]. Lepilliez et al. found that no delayed bleeding occurred in patients treated with prophylactic clipping or prophylactic argon plasma coagulation, or in patients treated for intraprocedural bleeding, whereas it occurred in $21.7 \%$ of patients with no intraoperative bleeding or bleeding prevention $(P=0.044)$ [74]. Nonaka et al. showed that the delayed bleeding rate dropped from $32 \%$ to $7 \%$ in cases of prophylactic clipping $(P<0.004)$ [76].

Therefore, prophylactic treatment of delayed bleeding is recommended, by placing hemoclips and ideally aiming at closing the mucosal defect when technically feasible. Alternatively, visible vessels can be treated with thermocoagulation or prophylactic hemoclips.

Immediate perforation is defined as a breach in the muscularis propria during endoscopic resection, usually explained by insufficient submucosal injection or fibrosis in the submucosa. Based on several retrospective studies, immediate perforation occurs in $2.2 \%$ to $6 \%$ of cases. Management of immediate perforation consists of completing the resection and then closing the perforation using hemoclips. Recently, Chung et al. report- 
- Table3 Published outcomes of endoscopic mucosal resection (EMR) for duodenal adenomas.

\begin{tabular}{|c|c|c|c|c|c|c|c|c|c|c|c|c|}
\hline \multirow[t]{2}{*}{ Year } & \multirow[t]{2}{*}{ Author } & \multirow[t]{2}{*}{ Type } & \multirow{2}{*}{$\begin{array}{l}\text { No. } \\
\text { pa- } \\
\text { tients }\end{array}$} & \multirow{2}{*}{$\begin{array}{l}\text { Mean } \\
\text { size [in- } \\
\text { terval] }\end{array}$} & \multirow{2}{*}{$\begin{array}{l}\text { Com- } \\
\text { plete } \\
\text { resec- } \\
\text { tion } \\
\text { rate (\%) }\end{array}$} & \multirow{2}{*}{$\begin{array}{l}\text { Fol- } \\
\text { low- } \\
\text { up } \\
\text { (mon- } \\
\text { ths) }\end{array}$} & \multirow[t]{2}{*}{$\begin{array}{l}\text { Tech- } \\
\text { niques }\end{array}$} & \multicolumn{2}{|c|}{$\begin{array}{l}\text { Immediate com- } \\
\text { plications (\%) }\end{array}$} & \multicolumn{2}{|c|}{$\begin{array}{l}\text { Delayed com- } \\
\text { plications (\%) }\end{array}$} & \multirow{2}{*}{$\begin{array}{l}\text { Recur- } \\
\text { rence } \\
\text { rate } \\
(\%)\end{array}$} \\
\hline & & & & & & & & $\begin{array}{l}\text { Bleed- } \\
\text { ing }\end{array}$ & $\begin{array}{l}\text { Per- } \\
\text { fora- } \\
\text { tion }\end{array}$ & $\begin{array}{l}\text { Bleed- } \\
\text { ing }\end{array}$ & $\begin{array}{l}\text { Per- } \\
\text { fora- } \\
\text { tion }\end{array}$ & \\
\hline 2020 & Probst et al. [42] & $\begin{array}{l}\text { Prospective (4 } \\
\text { years) }\end{array}$ & 110 & $\begin{array}{l}15 \mathrm{~mm} \\
{[4-70]}\end{array}$ & 94 & 48 & EMR & 0 & 2.2 & 13.5 & 1.1 & 20.4 \\
\hline 2020 & Na et al. [102] & $\begin{array}{l}\text { Retrospective } \\
\text { (10 years) }\end{array}$ & 59 & $\begin{array}{l}9 \mathrm{~mm} \\
{[5-14]}\end{array}$ & 81.4 & 15 & EMR & 5.1 & 5.1 & 0 & 0 & 0 \\
\hline 2019 & Hara et al. [44] & $\begin{array}{l}\text { Retrospective } \\
\text { (13 years) }\end{array}$ & 131 & $\begin{array}{l}9 \mathrm{~mm} \\
{[7-14.5]}\end{array}$ & 100 & 43 & EMR & 0 & 0 & 0 & 0 & 0 \\
\hline 2018 & Valerii et al. [48] & $\begin{array}{l}\text { Retrospective } \\
\text { (14 years) }\end{array}$ & 68 & $\begin{array}{l}26 \mathrm{~mm} \\
{[5-80]}\end{array}$ & 100 & 59 & EMR & 0 & 4 & 17.3 & 4.4 & NA \\
\hline 2018 & $\begin{array}{l}\text { Tomizawa et al. } \\
\text { [43] }\end{array}$ & $\begin{array}{l}\text { Retrospective } \\
\text { (9 years) }\end{array}$ & 142 & $\begin{array}{l}20 \mathrm{~mm} \\
{[7-55]}\end{array}$ & 92 & 9 & EMR & 7.8 & 0 & 5.6 & 0 & 23 \\
\hline 2017 & Valli et al. [71] & $\begin{array}{l}\text { Retrospective } \\
\text { (10 years) }\end{array}$ & 78 & $\begin{array}{l}17.2 \mathrm{~mm} \\
{[2-55]}\end{array}$ & 91 & 33 & EMR & 12.8 & 0 & 9 & 2,6 & 0 \\
\hline 2017 & Bartel et al. [72] & $\begin{array}{l}\text { Retrospective } \\
\text { (11 years) }\end{array}$ & 91 & $\begin{array}{l}22.5 \mathrm{~mm} \\
{[5-85]}\end{array}$ & 98.9 & 13 & EMR & 2.2 & 5.5 & 4.4 & 0 & 29 \\
\hline 2016 & Klein et al. [103] & $\begin{array}{l}\text { Retrospective } \\
\text { (8 years) }\end{array}$ & 106 & $\begin{array}{l}25 \mathrm{~mm} \\
{[19-40]}\end{array}$ & 100 & 22 & EMR & 43.4 & 0 & 15.1 & 2.8 & 14.4 \\
\hline 2012 & Fanning et al. [104] & $\begin{array}{l}\text { Retrospective } \\
\text { ( } 2 \text { years) }\end{array}$ & 46 & $\begin{array}{l}14.5 \mathrm{~mm} \\
{[5-25]}\end{array}$ & 94 & 24 & EMR & 36.9 & 2.2 & 4.3 & 4.3 & 17.5 \\
\hline 2010 & Abbass et al. [73] & $\begin{array}{l}\text { Retrospective } \\
\text { (6 years) }\end{array}$ & 59 & $\begin{array}{l}17.2 \mathrm{~mm} \\
{[3-50]}\end{array}$ & 93 & 26 & EMR & 0 & 0 & 5 & 0 & 37 \\
\hline 2008 & Lepilliez et al. [29] & $\begin{array}{l}\text { Retrospective } \\
\text { (8 years) }\end{array}$ & 36 & $\begin{array}{l}19 \mathrm{~mm} \\
{[4-50]}\end{array}$ & 100 & 15 & EMR & 13.9 & 2.8 & 11.6 & 0 & 0 \\
\hline 2005 & Apel et al. [75] & $\begin{array}{l}\text { Retrospective } \\
\text { (13 years) }\end{array}$ & 21 & $\begin{array}{l}27.5 \mathrm{~mm} \\
{[8-50]}\end{array}$ & 85 & 71 & EMR & 0 & 0 & 9.5 & 0 & 25 \\
\hline 2017 & Jamil et al. [69] & $\begin{array}{l}\text { Retrospective } \\
\text { (11 years) }\end{array}$ & 42 & $\begin{array}{l}25 \mathrm{~mm} \\
{[6-60]}\end{array}$ & 100 & 17 & $\begin{array}{l}\text { Cap- } \\
\text { EMR }\end{array}$ & 14.3 & 0 & 7.1 & 2.4 & 9.5 \\
\hline 2012 & Conio et al. [70] & $\begin{array}{l}\text { Retrospective } \\
\text { (10 years) }\end{array}$ & 26 & $\begin{array}{l}15 \mathrm{~mm} \\
{[15-80]}\end{array}$ & 100 & 72 & $\begin{array}{l}\text { Cap- } \\
\text { EMR }\end{array}$ & 11.5 & 0 & 0 & 0 & 11.5 \\
\hline
\end{tabular}

ed in seven patients the feasibility of suturing a duodenal EMR site, including cases of immediate perforation, using an endoscopic suturing device (Overstitch, Apollo Endosurgery, Austin, Texas, United States). While the device is costly and its maneuverability in the duodenum is questionable, endoscopic suturing systems are a promising path to decrease morbidity of duodenal EMRs. [78]. Usually, these complications have no clinical impact, since the resections are always performed with $\mathrm{CO}_{2}$ insufflation, and no fluid flows out of the duodenum. Therefore, after 24 hours of fasting, intravenous proton pump inhibitors, and prophylactic antibiotics, oral feeding is usually possible, provided the patient has no pain or fever and a normal blood count.

Delayed perforations occur after the end of the endoscopic procedure and are caused by thermal damage to the muscularis propria, possibly in conjunction with chemical aggression by bile acids. Delayed perforations occur in $1.7 \%$ to $4 \%$ of duode- nal EMRs. Clinical expression of delayed perforations can be abdominal pain, peritoneal syndrome, fever, or hemodynamic instability. A CT-scanner is usually performed to confirm the diagnosis. The management is challenging and involves gastroenterologists, digestive surgeons, and interventional radiologists. Typically, the duodenal perforation is closed, either surgically or endoscopically. Alternatively, it can be covered endoscopically by a covered duodenal stent. In addition, the peritoneal or retroperitoneal fluid collection should be drained by radiologically or surgically. Meanwhile, the patient is left nihil per os with continuous gastric aspiration, antibiotics and parenteral nutrition. All efforts are made to avoid an emergent pancreaticoduodenectomy, which is associated with a high mortality in this context. Delayed duodenal perforation is the most severe complication of this procedure, and accounts for the $1 \%$ mortality rate recorded after duodenal EMR even when performed by experienced teams. 


\section{A new treatment concept}

Underwater EMR is a modification of the conventional EMR technique, in which the duodenal lumen is filled with water. The duodenal wall is not stretched by (over) insufflation of $\mathrm{CO}_{2}$ and remains as thick as possible, so that submucosal injection is not needed. Consequently, the duodenal lesion is not enlarged by submucosal lifting, and easier to grasp with the snare. Four studies (2 prospective $[79,80]$ and two retrospective $[81,82]$ ) including a total of 161 patients, showed that underwater EMR is an efficient technique with an $87.5 \%$ to $100 \%$ complete endoscopic resections (no histological or endoscopic residual adenoma at the follow-up endoscopy) and $87 \%$ en bloc resections. The delayed bleeding rate was similar to that of conventional EMR, reaching $25 \%$ [80], while no perforation was recorded, and one case of water intoxication syndrome (hyponatremia and mental confusion) was recorded. Overall, this technique seems promising to increase the rate of en bloc resections, and possibly the rate of histologically complete resections leading to decreased recurrence rates. However, the current evidence mainly relies on a few uncontrolled studies performed by experts, and a recent comparative study did not show any benefit of underwater EMR over conventional EMR in terms of en bloc or histologically complete resection, or complication rates [82].

\section{Endoscopic submucosal dissection}

Endoscopic submucosal dissection (ESD) is an endoscopic resection technique developed in the early 2000's [83] that enables en bloc resection of large neoplastic lesions. Furthermore, the technique implies a step-by-step resection that allows resecting lesions with severe submucosal fibrosis, unamenable to EMR. Owing to the extremely low local recurrence rates after endoscopic submucosal dissection, the quality of the histological analysis allowed by en bloc resections, and acceptable complication rates, ESD has become the standard resection modality for esophageal and gastric neoplastic lesions [84].

Retrospective studies reported the outcomes of ESD in the duodenum, with a $75 \%$ to $100 \%$ en bloc resection rate (vs. $48 \%-56 \%$ for conventional EMR), no local recurrence (vs. $0 \%-$ $37 \%$ after conventional EMR), but a $8.8 \%$ to $35.7 \%$ of perforation rate, and $2 \%$ to $15.4 \%$ rate of emergency surgery $[48,72$, $74,75,85]$. Considering these numbers observed by extremely experienced Japanese teams, ESD for the resection of duodenal adenomas has currently not spread outside a few expert centers.

\section{Argon plasma coagulation}

APC is a hemostasis technique that can be used for electrocoagulation of submucosal vessels in order to prevent secondary bleeding. It also used for the destruction (also termed "ablation") of suspected residual adenoma on the margins of the mucosal resection. It has finally been proposed to directly ablate small $(<5 \mathrm{~mm})$ non-ampullary duodenal adenomas, in the setting of FAP, in order to downgrade the Spigelman stage. Three studies found this technique to be effective and safe with a recurrence rate of $10 \%$ to $38.4 \%$ and a bleeding rate of $6.25 \%$ to $7.7 \%[29,86,87]$. Currently, the resection or ablation of infracentimetric duodenal adenomas in FAP patients is not recommended, and the resection of sporadic non-ampullary duodenal adenomas is best achieved with cold resection snares [66].

\section{Surgical management}

There are three main surgical procedures allowing to resect duodenal adenomas [72,88-91]. Transduodenal excision allowing for a wedge, full thickness resection, and pancreas-sparing segmental duodenectomy are called the "limited resection" techniques, as opposed to pancreaticoduodenectomy.

Considering the progresses made by endoscopic therapy and the morbidity of surgical resections of the duodenum, the indications of surgery for duodenal adenomas in 2021 are limited: they include residual adenomas despite repeated endoscopic resection attempts, circumferential adenomas considered unamenable to endoscopic resection, and severe complications such as delayed perforation after endoscopic resection. In these cases, with a low or absent risk of lymph node metastases, limited resection techniques are indicated. For duodenal adenocarcinoma with submucosal invasion, either suspected on endoscopic ultrasound or documented after endoscopic resection, pancreaticoduodenectomy with lymph node resection should be performed, considering the risk of lymph node metastases.

\section{Pharmacological treatment of duodenal adenomas}

Medical treatment of duodenal adenomas is meant to reduce incidence of duodenal adenomas in patients with FAP and severe duodenal adenomatosis. Prophylactic colectomy has changed the prognosis in these patients, and duodenal cancer is now one of the main causes of cancer death in FAP patients. The main treatment approach leads to prevention of prostaglandin production by cyclo-oxygenase (COX). Nonsteroidal anti-inflammatory drugs (NSAIDs) inhibit the cyclooxygenases COX- 1 and COX-2, which are overexpressed in adenomatous tissue.

In the 1990 s, Sulindac, a NSAID already known to decrease the number and size of colorectal polyps in patients with FAP, has been tested versus placebo or calcium and calciferol in two prospective trials with disappointing results for duodenal adenomas $[92,93]$. More recently, Samadder et al., in a randomized controlled trial involving 92 patients, found sulindac and erlotinib, an EGFR inhibitor to significantly decrease the polyp burden (sum of the diameter of polyps) at 6 months compared to placebo [94]. However, the side effects (acne rash and oral mucositis) and costs of EGFR inhibitor have limited the diffusion of this treatment approach. Celecoxib, a COX-2 specific inhibitor, has been tested in a randomized placebo-controlled trial in 2002 by Phillips et al., and showed a statistically significant reduction of the number of duodenal adenomas at 6 months $(P=0.033)$ and a good tolerance [95]. These results still need to be confirmed over the long term and translated into clinically relevant endpoints. 
Ursodesoxycholic acid has also been tested in two prospective trials [96, 97] in 2012 and 2013 with negative results.

Finally, there are insufficient data to recommend chemoprevention of duodenal adenomas in patients with FAP. Although some expert centers do prescribe celecoxib to patients with severe duodenal lesions refractory to endoscopic therapy in patients reluctant to surgery, the ASGE only "recommends the use of chemopreventive agents within the confines of a tertiary hereditary cancer center and/or as part of clinical trials" [98].

\section{Management after endoscopic resection and follow-up}

Follow-up for patients with sporadic duodenal adenomas

The 2021 ESGE guidelines recommended to perform endoscopic surveillance 3 months after resection [64]. If no recurrence is found, a follow-up endoscopy should be performed 1 year later and then the rate of surveillance is adapted to the histological result, en bloc resection status, and lesion site.

In case of residual adenoma, endoscopic follow-up and further endoscopic treatments every 3 to 6 months until endoscopic and histologic remission of the adenoma are carried out.

\section{Follow-up for patients with duodenal adenomas and FAP}

The 2019 ESGE guidelines advise to start endoscopic surveillance at age 25 and to remove all adenomas $\geq 10 \mathrm{~mm}$ [31]. surveillance intervals range from 6 months to 5 years, depending on the Spigelman score and characteristics of the major duodenal papilla ( $>$ Table 4 ).

\section{Management of residual or recurrent adenomas}

Residual or recurrent adenomas are usually treated with a second EMR ( $\triangleright$ Fig. 3 ). In the absence of submucosal lifting due to scarring, cold snare resection or thermal ablation using APC can be attempted. In case of failure of these approaches, advanced resection procedures, such as endoscopic submucosal dissection, or full thickness endoscopic resection using a dedicated device [99], are interesting alternatives to surgery (ฉ Fig.4).

\section{Management of early duodenal adenocarcinoma}

Duodenal adenocarcinoma is a rare disease [100] and very little data are available on optimal management of T1 lesions. In a large study involving 46 patients with T1 duodenal adenocarcinomas and pancreaticoduodenectomy, Yoshimizu et al. found that no lymph node metastasis was observed in 34 patients with intramucosal cancers, while $42 \%$ (5/12) of patients with submucosal infiltration had lymph node metastases. As in other T1 adenocarcinomas of the digestive tract, presence of lymphovascular invasion or poor tumor differentiation grade significantly increased risk of lymph node metastases [101].

\section{Conclusion}

Non-ampullary duodenal adenomas are scarcely encountered lesions, with a neoplastic potential, following adenoma-carcinoma sequence. Their detection and resection can prevent the occurrence of duodenal adenocarcinoma, particularly in pa-
Table 4 Duodenal surveillance of patients with familial adenomatous polyposis.

\begin{tabular}{|l|l|l|}
\hline Spigelman Score & Spiegelman Stage & Surveillance interval \\
\hline 0 & 0 & 5 years \\
\hline $1-4$ & I & 5 years \\
\hline $5-6$ & II & 3 years \\
\hline $7-8$ & III & 1 years \\
\hline $9-12$ & IV & 6 months \\
\hline Characteristics of the ampulla of Vater & Surveillance interval \\
\hline Normal & 5 years \\
\hline Adenoma with LGD $<10$ mm & 3 years \\
\hline Adenomatous with LGD $\geq 10 \mathrm{~mm}$ & 1 year \\
\hline LGD, low-grade dysplasia & \\
\hline
\end{tabular}

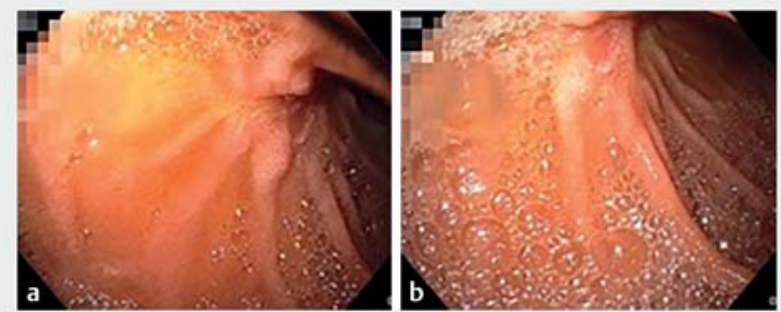

Fig. 3 Endoscopic follow-up after endoscopic mucosal resection showing a local recurrence $(A, B)$

tients with hereditary predisposition syndromes to gastrointestinal malignancies.

The diagnosis is based on a careful endoscopic examination, possibly requiring a side-viewing endoscope, and histology. Biopsies are best avoided, considering the risk of mucosal scarring that will affect the quality of the endoscopic resection.

While cold snare polypectomy is advisable for duodenal adenomas smaller than $6 \mathrm{~mm}$, EMR recommended for lesions $\geq 6$ $\mathrm{mm}$. En bloc resection is sought for lesions $\leq 20 \mathrm{~mm}$, and should be performed in tertiary referral centers as inpatient procedures. The two main complications of duodenal EMR are bleeding and perforation, managed endoscopically in the vast majority of cases. Despite providing higher en bloc resection rates, ESD has a limited contribution in management of duodenal adenomas because of a high perforation rate.

Considering the high risk of residual or recurrent adenoma, close endoscopic follow-up after endoscopic resection of a duodenal adenoma is recommended. In addition, screening colonoscopy should be performed in all patients with duodenal adenomas, owing to increased risk of colorectal neoplasia.

For FAP-related duodenal adenomas, endoscopy with indigo carmine chromoendoscopy is needed to increase visibility of duodenal lesions to best determine Spigelman stage, on which endoscopic surveillance relies. Endoscopic management aims 


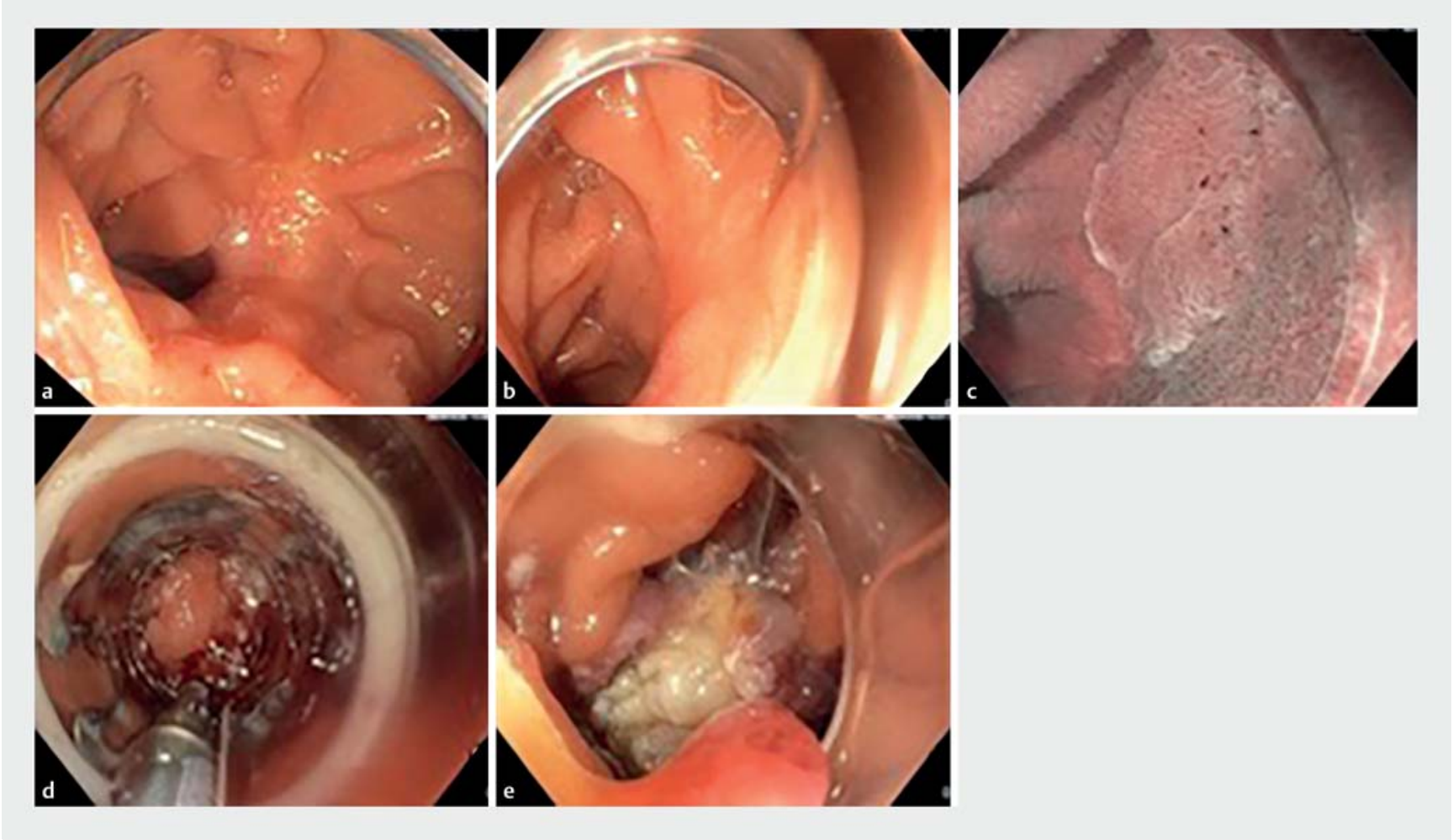

Fig. 4 Endoscopic characterization and treatment of a local recurrence at the genu inferius after three endoscopic mucosal resections. a, b White-light endoscopy, showing the attracted folds around the recurrent adenoma. c Virtual chromoendoscopie with NBI in an underwater view of the recurrent Paris 0-Ila adenoma recurrence. d,e Full-thickness resection or the recurrence using the endoscopic full thickness resection device (FTRD).

at preventing duodenal adenocarcinoma, by downstaging Spigelman score. This is achieved by performing resection of all supracentimetric duodenal adenomas. Chemoprevention of duodenal adenomas using NSAIDs or celecoxib can be offered to patients on a case-by-case basis to decrease adenoma burden.

\section{Competing interests}

MB discloses receiving honoraria from Medtronic and participation to boards for Norgine. The other authors did not disclose any conflict of interest

\section{References}

[1] Höchter W, Weingart J, Seib H-J et al. Duodenalpolypen: Häufigkeit, histologisches Substrat und Bedeutung. DMW - Dtsch Med Wochenschr 2008; 109: 1183-1186

[2] Dixon MF. Gastrointestinal epithelial neoplasia: Vienna revisited. Gut 2002; 51: 130-131

[3] Okada K, Fujisaki J, Kasuga A et al. Sporadic Nonampullary duodenal adenoma in the natural history of duodenal cancer: a study of followup surveillance. Am J Gastroenterol 2011; 106: 357-364

[4] Wagner PL, Chen Y-T, Yantiss RK. Immunohistochemical and molecular features of sporadic and FAP-associated duodenal adenomas of the ampullary and nonampullary mucosa. Am J Surg Pathol 2008; 32 : 1388-1395
[5] Rubio CA, Kaufeldt A, Kohan R et al. $\beta$-catenin Helices in the Cytoplasm of sporadic and FAP duodenal adenomas. Anticancer Res 2015: 35: $1433-1436$

[6] Niwa A, Kuwano S, Tomita $\mathrm{H}$ et al. The different pathogenesis of sporadic adenoma and adenocarcinoma in non-ampullary lesions of the proximal and distal duodenum. Oncotarget 2017: http://www. oncotarget.com/fulltext/17051 doi:10.18632/oncotarget.17051

[7] Hida R, Yamamoto H, Hirahashi M et al. Duodenal neoplasms of gastric phenotype: an immunohistochemical and genetic study with a practical approach to the classification. Am J Surg Pathol 2017; 41: 343-353

[8] Ushiku T, Arnason T, Fukayama M et al. Extra-ampullary duodenal adenocarcinoma. Am J Surg Pathol 2014; 38: 1484-1493

[9] Yoshida M, Shimoda T, Abe M et al. Clinicopathological characteristics of non-ampullary duodenal tumors and their phenotypic classification. Pathol Int 2019; 69: 398-406

[10] Ghazi A. Endoscopic Gastroduodenal polypectomy. Ann Surg 1984; 200: $175-180$

[11] Jung SH, Chung WC, Kim EJ et al. Evaluation of non-ampullary duodenal polyps: comparison of non-neoplastic and neoplastic lesions. World J Gastroenterol 2010; 16: 5474-5480

[12] Jepsen JM, Persson M, Jakobsen NO et al. Prospective study of prevalence and endoscopic and histopathologic characteristics of duodenal polyps in patients submitted to upper endoscopy. Scand J Gastroenterol 1994; 29: 483-487

[13] Ross R, Hartnett N, Bernstein L et al. Epidemiology of adenocarcinomas of the small intestine: is bile a small bowel carcinogen? Br J Cancer 1991; 63: 143-145 
[14] Yoshida M, Yabuuchi Y, Kakushima N et al. The incidence of non-ampullary duodenal cancer in Japan: The first analysis of a national cancer registry. J Gastroenterol Hepatol 2021; 36: 1216-1221

[15] Apel D, Jakobs R, Weickert $U$ et al. High frequency of colorectal adenoma in patients with duodenal adenoma but without familial adenomatous polyposis. Gastrointest Endosc 2004; 60: 397-399

[16] Murray MA. Sporadic duodenal adenoma is associated with colorectal neoplasia. Gut 2004; 53: 261-265

[17] Wu Z-J, Lin Y, Xiao J et al. Clinical Significance of colonoscopy in patients with upper gastrointestinal polyps and neoplasms: a meta-analysis. PLoS ONE 2014; 9: e91810

[18] Chathadi KV, Khashab MA, Acosta RD et al. The role of endoscopy in ampullary and duodenal adenomas. Gastrointest Endosc 2015; 82: 773-781

[19] Riemann JF, Hartmann D, Schilling D et al. Frequency of small bowel polyps in patients with duodenal adenoma but without familial adenomatous polyposis. Z Für Gastroenterol 2006; 44: 235-238

[20] Johnson MD, Mackey R, Brown N et al. Outcome based on management for duodenal adenomas: sporadic versus familial disease. J Gastrointest Surg 2010; 14: 229-235

[21] Bülow S. Duodenal adenomatosis in familial adenomatous polyposis. Gut 2004; 53: 381-386

[22] Bülow S, Christensen I], Højen $\mathrm{H}$ et al. Duodenal surveillance improves the prognosis after duodenal cancer in familial adenomatous polyposis: Duodenal surveillance improves the prognosis after duodenal cancer. Colorectal Dis 2012; 14: 947-952

[23] Spigelman AD, Talbot IC, Williams CB et al. Upper gastrointestinal cancer in patients with familial adenomatous polyposis. Lancet 1989; 334: 783-785

[24] Sourrouille I, Lefèvre JH, Shields C et al. Surveillance of Duodenal polyposis in familial adenomatous polyposis: should the Spigelman score be modified? Dis Colon Rectum 2017; 60: 1137-1146

[25] Latchford AR, Neale KF, Spigelman AD et al. Features of Duodenal cancer in patients with familial adenomatous polyposis. Clin Gastroenterol Hepatol 2009; 7: 659-663

[26] Groves C]. Duodenal cancer in patients with familial adenomatous polyposis (FAP): results of a 10 year prospective study. Gut 2002; 50 : 636-641

[27] Thiruvengadam SS, Lopez R, O’Malley M et al. Spigelman stage IV duodenal polyposis does not precede most duodenal cancer cases in patients with familial adenomatous polyposis. Gastrointest Endosc 2019; 89: 345-354.e2

[28] Saurin J-C, Gutknecht C, Napoleon B et al. Surveillance of duodenal adenomas in familial adenomatous polyposis reveals high cumulative risk of advanced disease. J Clin Oncol 2004; 22: 493-498

[29] Lepilliez V, Napoleon B, Lepilliez V et al. Endoscopic treatment of severe duodenal polyposis as an alternative to surgery for patients with familial adenomatous polyposis. Gastrointest Endosc 2014; 80: 817825

[30] Roos VH, Bastiaansen BA, Kallenberg FG] et al. Endoscopic management of duodenal adenomas in patients with familial adenomatous polyposis. Gastrointest Endosc 2020: S0016510720344230 doi:10.1016/j.gie.2020.05.065

[31] van Leerdam ME, Roos VH, van Hooft JE et al. Endoscopic management of polyposis syndromes: European Society of Gastrointestinal Endoscopy (ESGE) Guideline. Endoscopy 2019; 51: 877-895

[32] Bonadona V. Cancer risks associated with germline mutations in MLH1, MSH2, and MSH6 genes in Lynch syndrome. JAMA 2011; 305: 2304

[33] Giardiello FM, Allen JI, Axilbund JE et al. Guidelines on Genetic evaluation and management of Lynch Syndrome: a consensus statement by the US Multi-Society Task Force on Colorectal Cancer. Am J Gastroenterol 2014; 109: 1159-1179
[34] Vasen HFA, Blanco I, Aktan-Collan K et al. Revised guidelines for the clinical management of Lynch syndrome (HNPCC): recommendations by a group of European experts 12 .

[35] Schulmann K, Brasch FE, Kunstmann E et al. HNPCC-associated small bowel cancer: Clinical and molecular characteristics. Gastroenterology $2005 ; 128: 590-599$

[36] Hammoudi N, Dhooge M, Coriat R et al. Duodenal tumor risk in Lynch syndrome. Dig Liver Dis 2019; 51: 299-303

[37] Saurin J-C, Pilleul F, Soussan E et al. Small-bowel capsule endoscopy diagnoses early and advanced neoplasms in asymptomatic patients with Lynch syndrome. Endoscopy 2010; 42: 1057-1062

[38] Haanstra JF, Al-Toma A, Dekker E et al. Prevalence of small-bowel neoplasia in Lynch syndrome assessed by video capsule endoscopy. Gut 2015; 64: 1578-1583

[39] Vogt S, Jones N, Christian D et al. Expanded extracolonic tumor spectrum in MUTYH-associated polyposis. Gastroenterology 2009; 137: 1976-1985.e10

[40] Rayner E, van Gool IC, Palles C et al. A panoply of errors: polymerase proofreading domain mutations in cancer. Nat Rev Cancer 2016; 16: 71-81

[41] Hamzaoui N, Alarcon F, Leulliot N et al. Genetic, structural, and functional characterization of POLE polymerase proofreading variants allows cancer risk prediction. Genet Med 2020; 22: 1533-1541

[42] Probst A, Freund S, Neuhaus L et al. Complication risk despite preventive endoscopic measures in patients undergoing endoscopic mucosal resection of large duodenal adenomas. Endoscopy 2020: doi:10.1055/a-1144-2767

[43] Tomizawa Y, Ginsberg GG. Clinical outcome of EMR of sporadic, nonampullary, duodenal adenomas: a 10-year retrospective. Gastrointest Endosc 2018; 87: 1270-1278

[44] Hara Y, Goda K, Dobashi A et al. Short- and long-term outcomes of endoscopically treated superficial non-ampullary duodenal epithelial tumors. World J Gastroenterol 2019; 25: 707-718

[45] Goda K, Kikuchi D, Yamamoto Y et al. Endoscopic diagnosis of superficial non-ampullary duodenal epithelial tumors in Japan: Multicenter case series: Superficial non-ampullary duodenal tumors. Dig Endosc 2014; 26: 23-29

[46] Kakushima N. Endoscopic and biopsy diagnoses of superficial, nonampullary, duodenal adenocarcinomas. World J Gastroenterol 2015; 21: 5560

[47] Sellner F. Investigations on the significance of the adenoma-carcinoma sequence in the small bowel. Cancer 1990; 66: 702-715

[48] Valerii G, Tringali A, Landi R et al. Endoscopic mucosal resection of non-ampullary sporadic duodenal adenomas: a retrospective analysis with long-term follow-up. Scand J Gastroenterol 2018; 53: 490-494

[49] Kallenberg F, Bastiaansen B, Dekker E. Cap-assisted forward-viewing endoscopy to visualize the ampulla of Vater and the duodenum in patients with familial adenomatous polyposis. Endoscopy 2016; 49: 181-185

[50] Dekker E, Boparai K, Poley ] et al. High resolution endoscopy and the additional value of chromoendoscopy in the evaluation of duodenal adenomatosis in patients with familial adenomatous polyposis. Endoscopy 2009; 41: 666-669

[51] Kiesslich R, Mergener K, Naumann C et al. Value of chromoendoscopy and magnification endoscopy in the evaluation of duodenal abnormalities: a prospective, randomized comparison. Endoscopy 2003; 35: 559-563

[52] Hurley J], Thomas LE, Walton S-J et al. The impact of chromoendoscopy for surveillance of the duodenum in patients with MUTYH-associated polyposis and familial adenomatous polyposis. Gastrointest Endosc 2018; 88: 665-673 
[53] Blackman E, Nash SV. Diagnosis of duodenal and ampullary epithelial neoplasms by endoscopic biopsy: A clinicopathologic and immunohistochemical study. Hum Pathol 1985; 16: 901-910

[54] Kinoshita S, Nishizawa T, Ochiai Y et al. Accuracy of biopsy for the preoperative diagnosis of superficial nonampullary duodenal adenocarcinoma. Gastrointest Endosc 2017; 86: 329-332

[55] Kakushima N, Yoshida M, Yamaguchi Y et al. Magnified endoscopy with narrow-band imaging for the differential diagnosis of superficial non-ampullary duodenal epithelial tumors. Scand J Gastroenterol 2019; 54: 128-134

[56] Yoshimura N, Goda K, Tajiri H et al. Endoscopic features of nonampullary duodenal tumors with narrow-band imaging. Hepatogastroenterol 2010; 57: 462-467

[57] Kikuchi D, Hoteya S, lizuka T et al. Diagnostic algorithm of magnifying endoscopy with narrow band imaging for superficial non-ampullary duodenal epithelial tumors. Dig Endosc 2014; 26: 16-22

[58] Yao K, Iwashita A, Tanabe $\mathrm{H}$ et al. White opaque substance within superficial elevated gastric neoplasia as visualized by magnification endoscopy with narrow-band imaging: a new optical sign for differentiating between adenoma and carcinoma. Gastrointest Endosc 2008; 68: 574-580

[59] Yao K, Iwashita A, Nambu M et al. Nature of white opaque substance in gastric epithelial neoplasia as visualized by magnifying endoscopy with narrow-band imaging. Dig Endosc 2012; 24: 419-425

[60] Yamasaki Y, Takeuchi Y, Kanesaka T et al. Differentiation between duodenal neoplasms and non-neoplasms using magnifying narrowband imaging - Do we still need biopsies for duodenal lesions? Dig Endosc 2020; 32: 84-95

[61] Kakushima N, Yoshida M, Iwai T et al. A simple endoscopic scoring system to differentiate between duodenal adenoma and carcinoma. Endosc Int Open 2017; 5: E763-E768

[62] Azih LC. Endoscopic ultrasound evaluation in the surgical treatment of duodenal and peri-ampullary adenomas. World J Gastroenterol 2013; 19: 511

[63] Barat M, Dohan A, Dautry R et al. Mass-forming lesions of the duodenum: A pictorial review. Diagn Interv Imaging 2017; 98: 663-675

[64] Vanbiervliet G, Moss A, Arvanitakis M et al. Endoscopic management of superficial nonampullary duodenal tumors: European Society of Gastrointestinal Endoscopy (ESGE) Guideline. Endoscopy 2021; 53: 522-534

[65] Hamada K, Takeuchi Y, Ishikawa $\mathrm{H}$ et al. Feasibility of cold snare polypectomy for multiple duodenal adenomas in patients with familial adenomatous polyposis: a pilot study. Dig Dis Sci 2016; 61: 27552759

[66] Hamada K, Takeuchi Y, Ishikawa $\mathrm{H}$ et al. Safety of cold snare polypectomy for duodenal adenomas in familial adenomatous polyposis: a prospective exploratory study. Endoscopy 2018; 50: 511-517

[67] Patel N, Ponugoti P, Rex D. Cold snare polypectomy effectively reduces polyp burden in familial adenomatous polyposis. Endosc Int Open 2016; 04: E472-E474

[68] Maruoka D, Matsumura T, Kasamatsu S et al. Cold polypectomy for duodenal adenomas: a prospective clinical trial. Endoscopy 2017; 49: 776-783

[69] Jamil LH, Kashani A, Peter $\mathrm{N}$ et al. Safety and efficacy of cap-assisted EMR for sporadic nonampullary duodenal adenomas. Gastrointest Endosc 2017; 86: 666-672

[70] Conio M, De Ceglie A, Filiberti R et al. Cap-assisted EMR of large, sporadic, nonampullary duodenal polyps. Gastrointest Endosc 2012; 76: $1160-1169$

[71] Valli PV, Mertens JC, Sonnenberg A et al. Nonampullary duodenal adenomas rarely recur after complete endoscopic resection: a Swiss experience including a literature review. Digestion 2017; 96: 149157
[72] Bartel M], Puri R, Brahmbhatt B et al. Endoscopic and surgical management of nonampullary duodenal neoplasms. Surg Endosc 2018; 32: $2859-2869$

[73] Abbass R, Rigaux ], Al-Kawas FH. Nonampullary duodenal polyps: characteristics and endoscopic management. Gastrointest Endosc 2010; 71: 754-759

[74] Lépilliez V, Chemaly M, Ponchon T et al. Endoscopic resection of sporadic duodenal adenomas: an efficient technique with a substantial risk of delayed bleeding. Endoscopy 2008; 40: 806-810

[75] Apel D, Jakobs R, Spiethoff A et al. Follow-Up after Endoscopic Snare Resection of Duodenal Adenomas. Endoscopy 2005; 37: 444-448

[76] Nonaka S, Oda I, Tada K et al. Clinical outcome of endoscopic resection for nonampullary duodenal tumors. Endoscopy 2014; 47: 129135

[77] Aschmoneit-Messer I, Richl J, Pohl J et al. Prospective study of acute complication rates and associated risk factors in endoscopic therapy for duodenal adenomas. Surg Endosc 2015; 29: 1823-1830

[78] Chung J, Wang K, Podboy A et al. Endoscopic suturing for the prevention and treatment of complications associated with endoscopic mucosal resection of large duodenal adenomas. Clin Endosc 2021: doi:10.5946/ce.2020.281

[79] Yamasaki Y, Uedo N, Takeuchi Y et al. Underwater endoscopic mucosal resection for superficial nonampullary duodenal adenomas. Endoscopy 2017: doi:10.1055/s-0043-119214

[80] Binmoeller KF, Shah JN, Bhat YM et al. "Underwater" EMR of sporadic laterally spreading nonampullary duodenal adenomas (with video). Gastrointest Endosc 2013; 78: 496-502.e1

[81] Shibukawa G, Irisawa A, Sato A et al. Endoscopic mucosal resection performed underwater for nonampullary duodenal epithelial tumor: evaluation of feasibility and safety. Gastroenterol Res Pract 2018; 2018: 1-10

[82] Kiguchi Y, Kato M, Nakayama A et al. Feasibility study comparing underwater endoscopic mucosal resection and conventional endoscopic mucosal resection for superficial non-ampullary duodenal epithelial tumor $<20$ mm. Dig Endosc 2020; 32: 753-760

[83] Yamamoto H. Successful en-bloc resection of large superficial tumors in the stomach and colon using sodium hyaluronate and small-caliber-tip transparent hood. Endoscopy 2003; 35: 690-694

[84] Pimentel-Nunes P, Dinis-Ribeiro M, Ponchon T et al. Endoscopic submucosal dissection: European Society of Gastrointestinal Endoscopy (ESGE) Guideline. Endoscopy 2015; 47: 829-854

[85] Yahagi N, Kato M, Ochiai Y et al. Outcomes of endoscopic resection for superficial duodenal epithelial neoplasia. Gastrointest Endosc 2018; 88: 676-682

[86] Lienert A, Bagshaw PF. Treatment of duodenal adenomas with endoscopic argon plasma coagulation. ANZ J Surg 2007; 77: 371-373

[87] Min YW, Min B-H, Kim ER et al. Efficacy and safety of endoscopic treatment for nonampullary sporadic duodenal adenomas. Dig Dis Sci 2013; 58: 2926-2932

[88] Al-Sarireh B, Ghaneh P, Gardner-Thorpe J et al. Complications and follow-up after pancreas-preserving total duodenectomy for duodenal polyps. Br J Surg 2008; 95: 1506-1511

[89] Yan J-Q, Peng C-H, Yang W-P et al. Surgical management of benign duodenal tumours. ANZ J Surg 2010; 80: 526-530

[90] Kokosis G, Ceppa EP, Tyler DS et al. Laparoscopic Duodenectomy for Benign Nonampullary Duodenal Neoplasms. Surg Laparosc Endosc Percutan Tech 2015; 25: 158-162

[91] Abe N, Suzuki Y, Masaki T et al. Surgical management of superficial non-ampullary duodenal tumors. Dig Endosc Off J Jpn Gastroenterol Endosc Soc 2014; 26: 57-63

[92] Debinski HS. Effect of sulindac on small polyps in familial adenomatous polyposis. Lancet 1995; 345: 855-856 
[93] Seow-Choen F, Vijayan V, Keng V. Prospective randomized study of sulindacversus calcium and calciferol for upper gastrointestinal polyps in familial adenomatous polyposis. Br J Surg 1996; 83: $1763-$ 1766

[94] Samadder NJ, Neklason DW, Boucher KM et al. Effect of Sulindac and erlotinib vs placebo on duodenal neoplasia in familial adenomatous polyposis: a randomized clinical trial. JAMA 2016; 315: 1266

[95] Phillips RKS. A randomised, double blind, placebo controlled study of celecoxib, a selective cyclooxygenase 2 inhibitor, on duodenal polyposis in familial adenomatous polyposis. Gut 2002; 50: 857-860

[96] Parc Y, Desaint B, Fléjou J-F et al. The effect of ursodesoxycholic acid on duodenal adenomas in familial adenomatous polyposis: a prospective randomized placebo-control trial: Ursodesoxycholic acid in FAP patients. Colorectal Dis 2012; 14: 854-860

[97] van Heumen BW, Roelofs HM, Vink-Börger M et al. Ursodeoxycholic acid counteracts celecoxib in reduction of duodenal polyps in patients with familial adenomatous polyposis: a multicentre, randomized controlled trial. Orphanet J Rare Dis 2013; 8: 118

[98] Yang J, Gurudu SR, Koptiuch C et al. American Society for Gastrointestinal Endoscopy guideline on the role of endoscopy in familial adenomatous polyposis syndromes. Gastrointest Endosc 2020; 91: 963-982.e2
[99] Bauder M, Schmidt A, Caca K. Endoscopic full-thickness resection of duodenal lesions - a retrospective analysis of 20 FTRD cases. United Eur Gastroenterol J 2018; 6: 1015-1021

[100] Aparicio T, Henriques J, Manfredi $S$ et al. Small bowel adenocarcinoma: Results from a nationwide prospective ARCAD-NADEGE cohort study of 347 patients. Int J Cancer 2020; 147: 967-977

[101] Yoshimizu S, Kawachi H, Yamamoto Y et al. Clinicopathological features and risk factors for lymph node metastasis in early-stage nonampullary duodenal adenocarcinoma. J Gastroenterol 2020; 55: 754-762

[102] Na HK, Kim DH, Ahn JY et al. Clinical Outcomes following Endoscopic Treatment for Sporadic Nonampullary Duodenal Adenoma. Dig Dis 2020; 38: 364-372

[103] Klein A, Nayyar D, Bahin FF et al. Endoscopic mucosal resection of large and giant lateral spreading lesions of the duodenum: success, adverse events, and long-term outcomes. Gastrointest Endosc 2016; 84: 688-696

[104] Fanning SB, Bourke M], Williams S] et al. Giant laterally spreading tumors of the duodenum: endoscopic resection outcomes, limitations, and caveats. Gastrointest Endosc 2012; 75: 805-812 